\title{
Estimation of cellular manufacturing cost components using simulation and activity-based costing
}

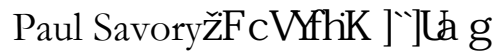 \\ University of Nebraska-Lincoln (USA)

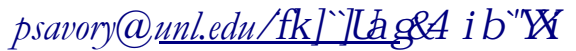

Received January 2010

Accepted June 2010

\begin{abstract}
It can be difficult estimating all of the cost components that are attributed to a machined part. This problem is more pronounced when a factory uses group technology manufacturing cells as opposed to a functional or process layout of a job shop. This paper describes how activity-based costing (ABC) concepts can be integrated into a discreteevent simulation model of a U-shaped manufacturing cell producing a part family with four members. The simulation model generates detailed Bills of Activity for each part type and includes specific information about the cost drivers and cost pools. The enhanced model output can be used for cost estimation and analysis, manufacturing cell design, part scheduling and other manufacturing decision processes that involve economic considerations. Although the scope of this effort is restricted to a small scale manufacturing cell, the costing concepts have general applicability to manufacturing operations at all levels.
\end{abstract}

Keywords: simulation, activity-based accounting, cost estimation, cellular manufacturing, group technology

\section{Introduction}

Low volume production techniques account for a large share of manufacturing operations. It is estimated that as much as 75 percent of all part manufacturing is performed with lot sizes of 50 or less (Groover, 1987). A typical job shop production system is characterized by low volume and high product variety. Parts 
are routed around the shop in small batches through a functional process layout. This type of layout and production system involves similar types of machines being grouped into physically separate areas of a facility.

One of the more effective methods for a traditional job shop to improve its manufacturing efficiency is through the application of group technology. Group technology is a manufacturing philosophy that takes advantage of the similarities in the design and manufacturing attributes of production parts (Groover, 1987). Similar parts are grouped together into part families. Efficiency is gained by arranging the production equipment into manufacturing cells to facilitate work flow and reduce the inherent inefficiencies of batch production (Groover, 1987; Dhavale, 1993). In a comparison of a traditional job shop to a manufacturing cell using group technology, Flynn and Jacobs (2007) found that the group technology design, on average, had shorter setup times, lower machine utilization, and shorter distances traveled.

However, the efficiency gained with cellular manufacturing may not be accurately reflected in the product costs if the company uses the traditional accounting practices of a typical job shop environment (Dhavale, 1992). Today's manufacturing processes are much more automated and the direct labor percentage is therefore significantly reduced. Additionally, overhead costs have greatly increased. The traditional volume-based costing (VBC) methods are less meaningful with this increase in the relative amount of non-direct costs (Barth, Livet, \& De Gui, 2008; Harrison and Sullivan, 1996). Moreover, an operator may tend to several machines at one time and may perform tasks such as inspection and maintenance that are considered indirect labor. This makes it difficult to account for all of an operator's time and to partition the cost spent only on direct labor (Dhavale, 1992).

As a solution, activity-based costing ( $A B C)$, also called activity-based cost accounting, attempts to eliminate the distinction between direct and indirect costs by improving the reporting precision of non-direct costs or overhead (Lere \& Saraph, 2006; Dhavale, 1992; Harrison and Sullivan, 1996). While ABC was developed for understanding manufacturing costs, its application is available for many types of systems (Raab, Shoemaker, \& Mayer, 2007). To be truly useful, one needs to estimate the manufacturing costs under alternate configurations, and with 
various capacity, resource, and product mix scenarios. Discrete-event simulation is one of the best techniques to study and compare these scenarios. Usually simulation focuses on evaluating system performance variables such as resource utilization, inventory levels, and throughput time. A cost analysis is typically performed separately of the simulation model development. This research highlights the integration of the two.

There are three methods for incorporating cost estimation with simulation (Savory, Williams, \& Rasmussen, 2001). The first involves incorporating costing extensions into the simulation language or package. An example of this would be the commercially-available simul8 simulation software. A disadvantage is that many times only superficial costing information is presented and the specific details of how the costs are determined are unknown to the modeler. The second approach involves developing costing estimates off-line during a post-processing step that uses the final system performance measures generated by the simulation. This is the most common approach in that a modeler takes the simulation results and converts them to costs. A disadvantage is that costing estimates are developed based on aggregate simulation data and often times does not account for the underlying randomness and variability of part processing and system interaction. A final approach incorporates costing routines directly into the simulation model and collects data on-line during the execution of the model. As this research will highlight, one of its key advantages is that non-allocated costs associated with idle time can be tracked.

This paper discusses the positive integration of $A B C$ and discrete-event simulation to provide detailed estimates of cellular manufacturing costs for a part family and U-shaped manufacturing cell. Section 2 provides an overview of activity-based cost accounting. Section 3 describes an example cellular manufacturing system. Section 4 develops the cost drivers and activity centers for the manufacturing cell example. Section 5 shares details on the simulation model development. Section 6 highlights the costing reports generated by the simulation model for the example cellular manufacturing system. Section 7 concludes with a discussion of the relevance of the research. 


\section{Uses of activity-based costing and simulation}

John Deere \& Company is credited with coining the term "activity-based costing" in 1984. A pilot study at their Component Works division showed that $A B C$ resulted in more competitive bidding and transfer pricing, better process scheduling, and more efficient machine configuration (MacArthur, 1992). They also found that $A B C$ provided more accurate costs of individual castings due to the overhead assignment based on manufacturing activities in comparison to their previous system of allocating overhead based on direct labor hours.

The concept of $A B C$ is based on the realization that products require businesses to perform activities (work generating processes or procedures). Those activities in turn drive the business to incur associated costs. These costs fall into two general categories: (1) costs directly tied to a product flow, and (2) those costs not tied to a product flow. Costs that are traceable to a product flow are ultimately assigned to the product (Barth et al., 2008). The costs not associated with product flow are assigned to the activities that make the costs necessary (Williams, Savory, \& Rasmussen, 1997; Hicks, 1992).

Harrison and Sullivan (1996) highlight the difference between $A B C$ and the traditional VBC for a manufacturing system with four products. Their example shows that VBC undercosts three of the items and overcosts the fourth. The authors also found that as overhead increased, the cost methodology became more important. Absolute differences in unit product costs increased with higher overhead. Shields and McEwen (1996) surveyed over 140 companies regarding the objectives and results of implementing $A B C$. The majority of the respondents listed better cost information as their original objective. When asked about the future goals for their $A B C$ system, product costing was the most common response.

Developing $A B C$ costing estimates using simulation has been explored by several researchers (Helberg, Galletly, \& Bicheno, 1994; Emblemsvag, 2003; Özbayrak, Akgün, \& Türker, 2003; Spedding and Sun, 1999). Mangan (1995) discusses the design and implementation of $A B C$ in the semiconductor sector of Harris Corporation. One of the major benefits of their $A B C$ implementation was that product costs gained credibility within the company since it allowed them to accurately determine whether to outsource products or to make cost-saving inhouse process improvements. Malik and Sullivan (1995) developed a mixed integer 
programming model which utilized $A B C$ information to determine optimal product mix and product cost in a multi-product manufacturing environment. They found that their approach, which incorporated more specific information on indirect cost consumption, produced different results when compared to the traditional costing system.

\section{Description of the manufacturing cell}

The manufacturing efficiency of a company that uses low volume batch production can be improved by rearranging the equipment into cells to facilitate work flow (Groover, 1987). A hypothetical manufacturing cell and part family were considered. The cell is abstracted from a real manufacturing system and contains issues significant in most production environments (e.g., breakdowns, part routings, preventive maintenance, batch processing). The cell is shown in Figure 1 and represents a typical U-shaped or loop layout. The cell consists of four machines: two identical computer numerically controlled (CNC) lathes, one CNC machining center, and one universal grinder. The first lathe contains all tooling and fixtures to machine one side of a rotational part, while the second lathe is used to machine the opposite side of the part.

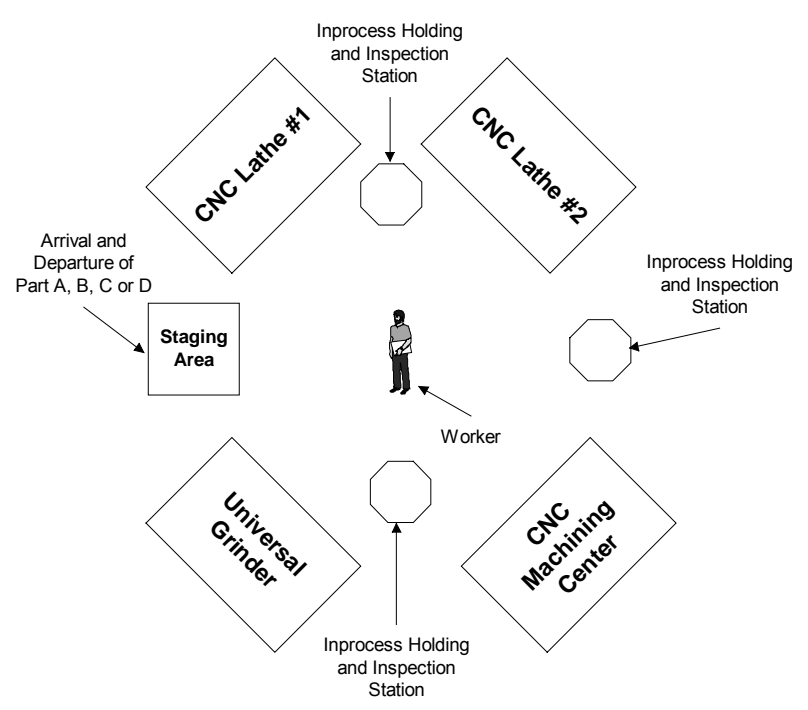

Figure 1. "U-shaped cell configuration".

The cell is run by a single operator who is responsible for all setup, loading/unloading, processing, material handling, and quality control inspections 
for parts on all four machines. The operator processes requests on a first-in, firstout basis with no pre-emption. In such an implementation, there is the potential that production time on one machine is lost while the worker is completing a task on another machine.

Table 1 shows the purchase price, useful life, and other pertinent data of the four machines comprising the cell. In addition to the machine costs, direct and indirect labor rates were assumed to be $\$ 12$ per hour with a 30 percent benefit rate. Hourly preventative and repair maintenance rates (including parts and labor) were assumed to be $\$ 50$ and $\$ 200$, respectively. All costs are in US dollars.

\begin{tabular}{|l|c|c|c|c|c|}
\hline \multicolumn{1}{|c|}{ Machine } & $\begin{array}{c}\text { Purchase } \\
\text { Cost }\end{array}$ & $\begin{array}{c}\text { Life In } \\
\text { Years }\end{array}$ & $\begin{array}{c}\text { Power } \\
\text { Consumption }\end{array}$ & $\begin{array}{c}\text { Utility } \\
\text { Rate }\end{array}$ & $\begin{array}{c}\text { Consumables } \\
\text { Rate }\end{array}$ \\
\hline CNC Lathe \#1 & $\$ 120,000$ & 10 & 20 kilowatts & $\$ 0.04 /$ hour & $\$ 2.00 /$ hour \\
\hline CNC Lathe \#2 & $\$ 120,000$ & 10 & 20 kilowatts & $\$ 0.04 /$ hour & $\$ 2.00 /$ hour \\
\hline CNC Machining Center & $\$ 100,000$ & 10 & 25 kilowatts & $\$ 0.04 /$ hour & $\$ 2.50 /$ hour \\
\hline Universal Grinder & $\$ 80,000$ & 10 & 15 kilowatts & $\$ 0.04 /$ hour & $\$ 1.75 /$ hour \\
\hline
\end{tabular}

Table 1. "Machine cost and usage information".

The part family consists of four part types ( $, B, C$ and D) each requiring different processing sequences. Part arrivals to the cell occur in homogeneous batches of a specific part type. Batch sizes for each part type and the sequence for processing are shown in Table 2. Batch arrivals occur based on an exponential distribution with a mean of four hours and forty minutes. Part type determination is based on production mix requirements of $30 \%$ type A, $20 \%$ type $B, 40 \%$ type C, and $10 \%$ type D.

\begin{tabular}{|c|c|c|c|c|c|}
\cline { 3 - 6 } \multicolumn{2}{c|}{} & \multicolumn{4}{c|}{ Production Sequence } \\
\hline Part Type & Batch Size & CNC Lathe \# 1 & CNC Lathe \#2 & CNC Machining & Universal Grinder \\
\hline A & 4 & 1 & 2 & 3 & 4 \\
\hline B & 3 & 1 & 2 & N/A & 3 \\
\hline C & 6 & 1 & 2 & 3 & N/A \\
\hline D & 2 & 1 & 2 & N/A & N/A \\
\hline
\end{tabular}

Table 2. "Part family characteristics and sequence of stations for each part type".

The cell operates for two consecutive eight-hour shifts over a six-day work week. Production scheduling is based on completing at least 1080 part type A's, 720 part type B's, 1440 part type C's, and 360 part type D's within 51 weeks of annual operation.

Setups are accomplished for each batch with the time dependent on whether the previous batch was of the same part type or not. If the previous batch was the 
same part type as the current batch, then a short setup is accomplished, otherwise a long setup is performed. The notion of the short setup takes advantage of the much fewer tooling changeovers required with similar part types. The probability distributions for the short and long setup times at each station are:

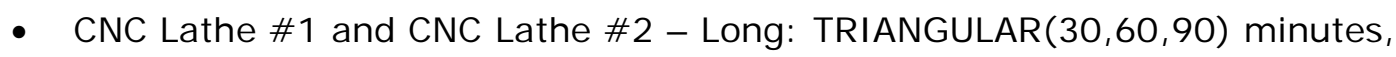

- CNC Lathe \#1 and CNC Lathe \#2 - Short: $\operatorname{TRIANGULAR(30,60,90)/4}$ minutes,

- CNC Machining - Long: TRIANGULAR(30, 45, 60) minutes,

- CNC Machining - Short: TRIANGULAR(30, 45, 60)/4 minutes,

- Universal Grinder - Long: TRIANGULAR(20,40,60) minutes,

- Universal Grinder - Short: TRIANGULAR(20,40,60)/4 minutes.

All other times within the cell are based on actions involving individual parts rather than batches. After the batch setup is done, an individual part is selected, moved to the machine, loaded, processed, unloaded, moved to the in-process inspection station, and inspected. This cycle is accomplished at each station until all parts within the batch are complete. Distributions representing part loading, unloading and inspection times were common to all four station:

- Part Loading Time: NORMAL(3, 0.5) minutes,

- Part Unloading Time: NORMAL(2,0.25) minutes,

- Part Inspection Time: UNIFORM(1.5,2.0) minutes.

Part processing time distributions (the same for each part type) at each station are:

- CNC Lathe \#1: TRIANGULAR(10, 15, 20) minutes,

- CNC Lathe \#2: TRIANGULAR(10, 15, 20) minutes,

- CNC Machining: TRIANGULAR(10, 20, 30) minutes,

- Universal Grinder - Long: TRIANGULAR(10,20,30) minutes. 
Material handling or move times are based on distances between the various stations and the time for the respective operator to travel from one point to another. Because of the small distances, the material handling times, on the order of 15 to 20 seconds, are relatively small in comparison to other times considered within the cell.

\section{Development of cost drivers and activity centers}

Since activities require resources to be consumed and products require activities to be performed, an ABC implementation is designed as a two-stage process. The first stage transfers costs associated with resource consumption and support to activities, while the second stage allocates activity costs to products. The mechanisms used to transfer costs at the first stage are called first-stage cost drivers or resource drivers. At the second stage, they are referred to as secondstage cost drivers or activity drivers. The production of parts, for example, requires raw materials, batch setups, material handling, and processing. Each of these require resources in terms of purchasing and receiving actions, indirect labor, direct labor, machine usage with associated depreciation costs, consumable supplies, and electrical power. As such, cost drivers are the metrics used to translate resource consumption, support, and activity into costs for allocation at the appropriate level (Williams et al., 1997).

One of the key concepts in $A B C$ is defining an activity center. An activity center is a collection of activities that a manager would like to effectively control and are often homogeneous processes. Examples include a manufacturing cell, machining or assembly functions, or a business process such as procurement or marketing (Dhavale, 1992). With $A B C$, costs associated with resource consumption are first grouped into cost pools at each activity center. Cost pooling gives managers the data necessary for planning and controlling activities and for measuring activity center performance (Michalska \& Szewieczek, 2007). An activity center can have one or more cost pools, but each cost pool requires homogeneity within the pool since only one cost driver is assigned for each cost pool. However, one must realize that some costs are triggered at the unit, batch, or by the product level (Williams et al., 1997). 


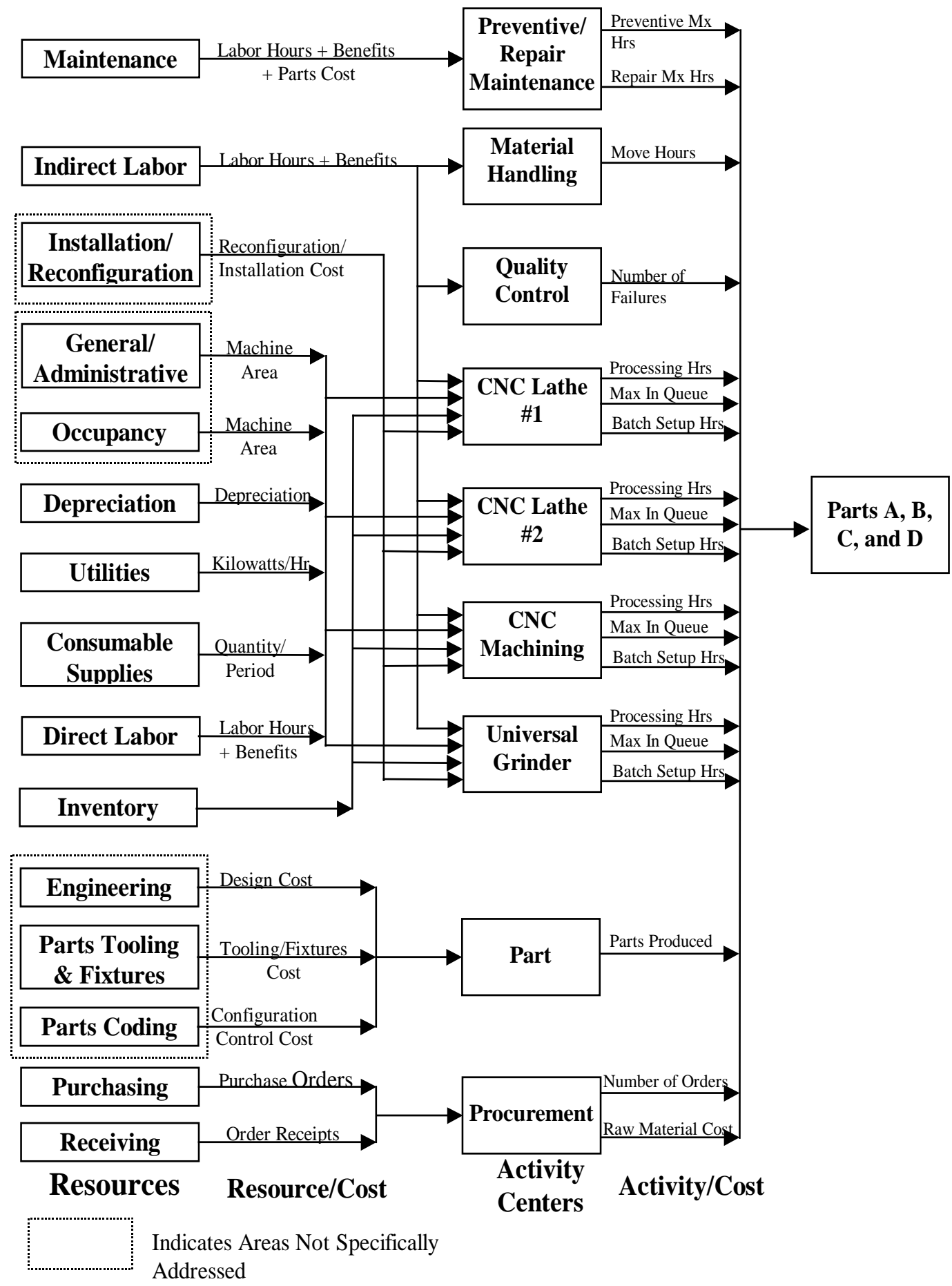

Figure 2. "Activity-based costing representation for the manufacturing cell".

Figure 2 provides a generalized activity-based costing depiction for the example manufacturing cell. The resources and activity centers that are shown are not meant to be all inclusive but simply representative of a typical manufacturing cell. Areas highlighted by a dotted box were not addressed as part of this research. If 
the effort had been developed for an existing manufacturing facility, this information would have been available and could easily be included.

A total of nine activity centers are specified. Each machine in the cell is designated as its own activity center. Other activity centers are designated for maintenance, material handling, quality control, part and procurement. These activity centers are required in order to provide detailed manufacturing cost estimates.

While Figure 2 provides an overview of how costs are transferred, an $A B C$ implementation requires specific cost transfer mechanisms to be defined in terms of mathematical equations. Equations for cost terms include: (1) the accumulation of all costs to provide the per unit cost for part type i (A, B, C, or D); (2) the per unit development cost for part type i; (3) the per unit procurement cost for part type i; (4) the within-cell per unit material handling costs for part type i; (5) the per unit inspection/quality control cost for part type $i$; $(6)$ the per unit maintenance cost based on part family; (7) the per unit production cost for part type $i$ on machine j (CNC Lathe \#1, CNC Lathe \#2, CNC Milling Machine, Universal Grinder), and $(8)$ the per unit inventory costs for machine $j$. The specific equations are:

$$
\begin{gathered}
\mathbf{C} p c_{i}=\mathbf{C} d v_{i}+\mathbf{C} m_{i}+\mathbf{C} m h_{i}+\mathbf{C} q c_{i}+\mathbf{C} m x+\sum_{j} \mathbf{C} p_{i j} \\
\mathbf{C} d v_{i}=\frac{1}{\sum_{i} \mathbf{N} l t_{i}}\left(\mathbf{C} e_{i}+\mathbf{C} c_{i}+\mathbf{C} t_{i}\right) \\
\mathbf{C} m_{i}=\frac{\mathbf{R o p} * \mathbf{N} o_{i}+\mathbf{R} m_{i} * \sum_{\mathbf{j}} \mathbf{N} q_{i}}{\mathbf{N} h_{i}} \\
\mathbf{C} m h_{i}=\frac{1}{\mathbf{N} a_{i}} \sum_{j} \mathbf{R} l m h^{*} \mathbf{T} m h_{i j} \\
\mathbf{C} q c_{i}=\frac{1}{\mathbf{N} a_{i}} \sum_{j}\left(\mathbf{R} l q c^{*} \mathbf{T} q c_{i, j}+\mathbf{R} q c^{*} \mathbf{N} p_{i j}\right) \\
\mathbf{C} m x=\frac{1}{\sum_{i} \mathbf{N} a_{i}} \sum_{j}\left(\mathbf{R} p m^{*} \mathbf{T} p m_{j}+\mathbf{R} r m_{i j} * \mathbf{T} r m_{j}\right) \\
\frac{1}{\mathbf{N} a_{i}} \sum_{j}\left[\left(\mathbf{R} g a_{j}+\mathbf{R} o c_{j}+\mathbf{R} i r_{j}+\mathbf{R} d p_{j}+\mathbf{R} p_{j}+\mathbf{R} c s_{j}\right) * \mathbf{T} p_{i j}+\mathbf{R} l p * \mathbf{T} l p_{i j}+\left(\mathbf{R} d s u_{j}+\mathbf{R} l s u+\mathbf{R} c s_{j}\right) * \mathbf{T} s u_{i j}\right] \\
\mathbf{C} I_{j}=\frac{\mathbf{N} I_{j} * \mathbf{R} I}{\sum_{i} \mathbf{N} a_{i}}
\end{gathered}
$$

Definitions of the specific terms and variables used in the equations can be found in the Appendix. As an example, consider the per unit cost for part type $A$ (equation $1=(p c A$ ). This cost is the sum of the per unit development cost of part 
A (cdvA), the per unit procurement costs of part type $A(\mathrm{cmA})$, the per unit material handling cost of part type $A(\mathrm{cmhA})$, the per unit inspection/quality control cost for part type $A$ (cqcA), the per unit maintenance cost $(\mathrm{cmx})$, and the per unit production cost for part type A on machines 1, 2, 3, and $4\left(\sum \mathrm{cpAj}\right)$. As discussed in the next section, these cost components are collected and recorded during the execution of the simulation model.

\section{Simulation model development}

A discrete-event simulation model of the manufacturing cell was developed in the SIMAN simulation language. Parts (entities) arrive in batches to CNC Lathe \#1 (according to Table 2). Upon a batches arrival, the operator and machine are occupied for a set-up time. Depending upon if the batch type is the same as the previous batch, a long or short set-up delay occurs (triangular distribution). After the machine is set-up, the operator loads an individual part on the machine (normal distribution) and the part is processed (triangular distribution). During the part processing, the operator is free to attend to other activities in the cell. After processing is complete and the operator is free, the part is unloaded (normal distribution) and inspected (uniform distribution). Once all the parts in a batch are processed, the batch can be moved to CNC Lathe \#2. Each of the machining stations operates similar to this first one. The specific parameter values for the probability distributions are described in Section 2.

The stochastic or random components of the simulation model include: time between batch arrival, part type per batch, load time for a part on a machine, setup time for a part on a machine, processing time for a part on a machine, unload time for a part at a machine, inspection time of a part, time to complete a preventive maintenance (partial and full), time between a machine failure, and time for a machine repair.

To collect the processing time and cost components as outlined by Figure 2 and the cost equations in the previous section, the simulation model uses an attributebased modeling approach. For instance, each part has an attribute that identifies it as a part type A, B, C, or D. Additionally, as the part (entity) proceeds through the simulation of the cell, different attributes record the time delays associated with batch setup time, part loading time, processing time, inspection time, unloading 
time, and part movement time. When all processing is complete on a part (entity), the information is accumulated in a set of SIMAN variables by part type and machine in order to establish costs.

The simulation program also determines non-allocated costs. Examples would include operator idle-time costs and unused or excess capacity costs. Operator idle-time costs reflect the amount of time that the operator is not busy moving parts, loading or unloading the machines, performing setups, or inspecting parts. Unused capacity costs are based on machine depreciation and the difference between actual and scheduled production time. In a perfect scheduling environment there would be no unused capacity costs. However, anytime production is finished prior to the scheduled completion, there is a portion of the depreciation costs that are unallocated. This can be viewed as an opportunity since excess capacity can be used for processing other products or completing other tasks.

All data collection and cost estimation is performed using the constructs of the SIMAN simulation language. There is no user-written inserts or code linked into the simulation model. To achieve this, SIMAN blocks/variables such as MREP, NREP, WRITE, READ, and WHILE were used. The only SIMAN summary statistics used by the cost accounting procedure are related to preventive and repair maintenance actions. In these instances, frequency times and totals were used to establish the total time for each type of maintenance action.

A total of thirty replications were run for the simulation model of the manufacturing cell. Each replication of the model simulates 51 weeks of operation. After each replication is complete, the model writes the accumulated costing information to a data file. After the thirtieth replication, all of the information from the data file is read back into the simulation model and used to calculate estimates for the cost parameters. The simulation model next generates a Bill of Activity for the part family, for each part type, and for each major activity center.

\section{Costing results and analysis}

Figure 3 shows the part family Bill of Activity generated for the U-shaped manufacturing cell. It presents the average costs for the thirty replications of the simulation model. Given managers and executives often make decisions based on 
simple cost estimates, the model only reports the mean cost for the 30 replications rather than generating and reporting confidence intervals. The average manufacturing cost per unit is $\$ 35.38$. The average total and per unit costs are listed for each of the main activity centers of the cell. One key feature of this Bill of Activity is the estimated non-allocated cost associated with operator idle time. The average idle time cost for the operator for the simulated 51 weeks is $\$ 17,393.73$.

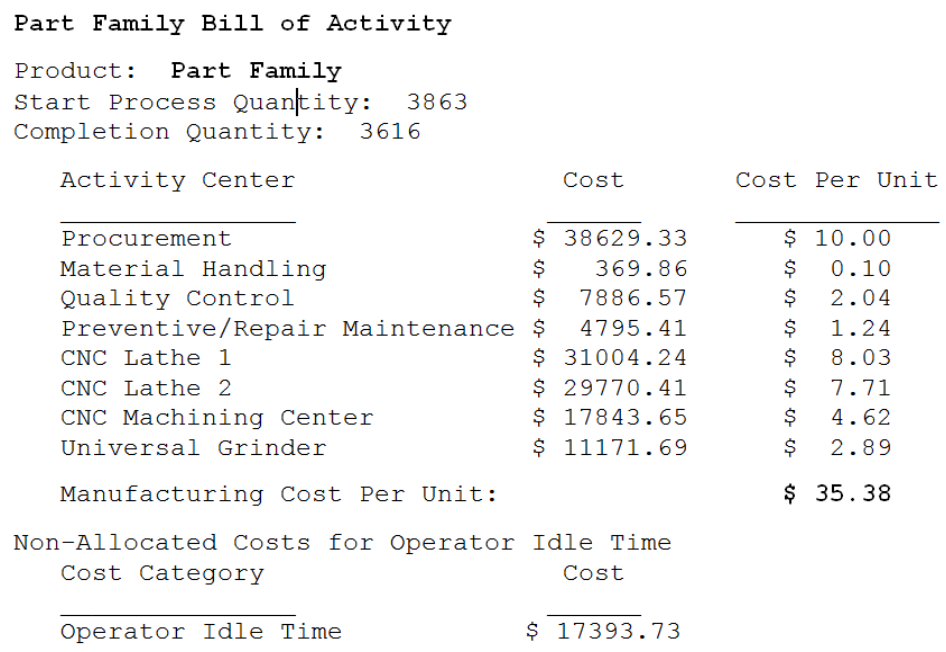

Figure 3. "Part family bill of activity with non-allocated costs".

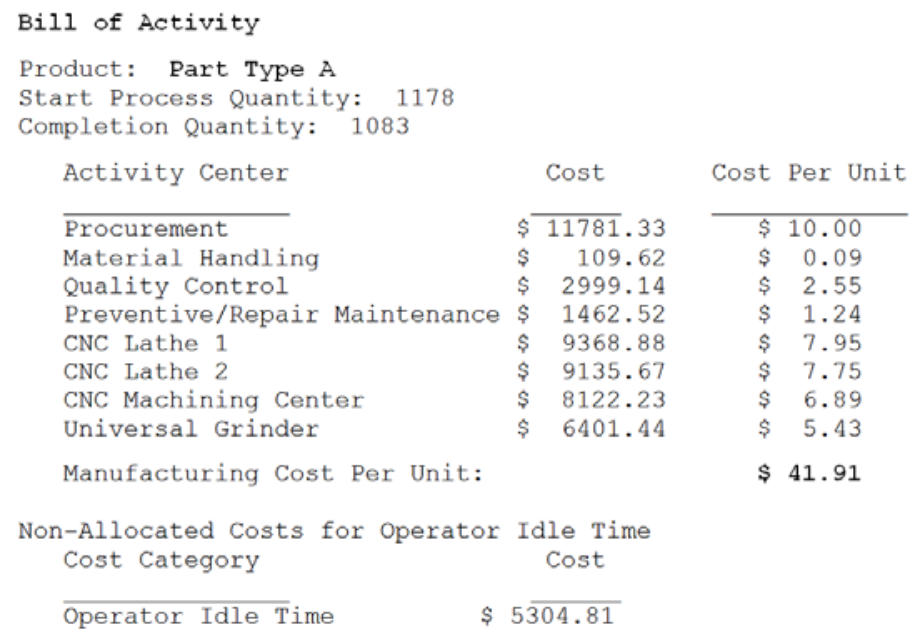

Figure 4. "Bill of activity for part type A"

Part type Bills of Activity for generated for each member of the part family (A, B, C, and $D$ ). As an example, the Bill of Activity for part type $A$ is shown in Figure 4 . The 
manufacturing cost per unit for part $A(\$ 41.91)$ is significantly higher than the average cost per unit for the entire family $(\$ 35.38)$. This is due to the fact that part A's processing sequence includes all of the four machines in the cell. The other part family members only require processing at two or three machines and have less cost. Similar bills are generated by the simulation for each of the other part types.

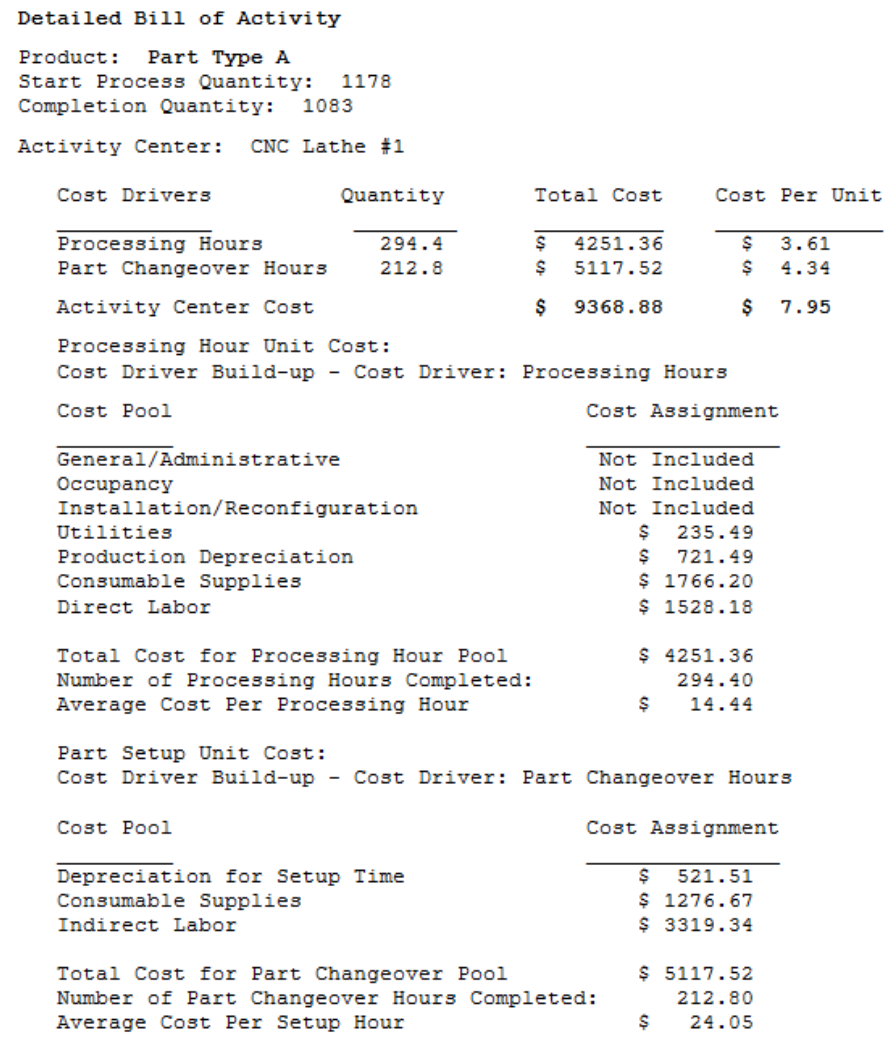

Figure 5. "Detailed bill of activity for part type a showing CNC lathe \#1 activity center".

The Detailed Bill of Activity for a part type also lists the cost drivers and cost pools (Figure 2) estimated by the 30 replications of the simulation model. Figure 5 shows a Detailed Bill of Activity for part type A and the CNC Lathe \#1 activity center. It shows that the total CNC Lathe \#1 cost attributed to producing the part type A's is $\$ 9,368.88$ at a cost of $\$ 7.95$ per unit. For the processing hours cost driver, the relevant cost pools include utilities, depreciation, consumable supplies, and direct labor. Specifically, to produce all the part type A's required $\$ 235.49$ in utilities, $\$ 1,766.20$ in consumable supplies, and $\$ 1,528.18$ in direct labor of the one worker. The other cost drivers concern the cost for part setup or changeover hours and 
indirect labor. This type of detailed costing information is generated by the simulation model for each part type and each activity center.

\section{Conclusion}

The application of group technology part families and manufacturing cells is an effective method for improving manufacturing operations. However, the improved manufacturing efficiency may not be fully reflected with traditional volume-based costing (VBC) methods. This research demonstrates the positive integration of activity-based costing $(A B C)$ with a discrete-event simulation model to provide more accurate estimates of manufacturing cost components. Key outcomes include: (1) reviewing how cost estimation and simulation can be combined, (2) integrating activity-based costing concepts into the discrete-event simulation model of a hypothetical U-shaped manufacturing cell, (3) having the simulation model produce detailed bills of activity that break down part manufacturing costs for each activity performed within the cell during the processing of the part family, and (4) developing estimates of the non-allocated costs such as operator idle-time costs and unused or excess capacity costs.

For an analysis technique to be useful, the output it produces must be understandable to all levels of an organization. Barth et al. (2008) comments, "The accurate evaluation of production costs has become absolutely essential for companies today." While simulation models traditionally help in the estimation of production metrics such as machine utilization, processing time, and throughput times, the cost of a system/part is a universal performance characteristic. By integrating $\mathrm{ABC}$ concepts with simulation, the added costing information provides an economic assessment of the system being evaluated and allows better decisions to be made at all levels of an organization (O'Loughlin, Driskell, \& Diehl 1990).

Although the scope of this research was restricted to a single group technology manufacturing cell, the costing concepts and equations have general applicability to other types of manufacturing and production systems including job shops, batch production, and flexible manufacturing systems. Potential applications include part pricing, cell design, identifying costly production tasks, determining the impact of part sequencing and scheduling decisions, and evaluation of product mix changes for a part family. Overall, the integration of $A B C$ concepts with a discrete-event 
simulation model can supplement traditional performance metrics with costing information for determining the best system configuration with the appropriate labor resource level.

\section{Appendix - Nomenclature for Terms in Cost Equations}

\section{Time:}

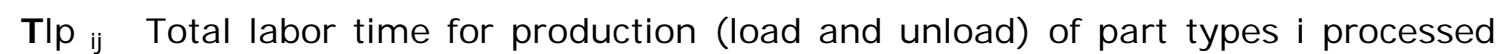
on machine $\mathrm{j}$

$\mathbf{T p}_{\mathrm{ij}}$ Total machine time for production (load, process, and unload) of part types $\mathrm{i}$ processed on machine $\mathrm{j}$

Tsu ${ }_{\mathrm{ij}}$ Total time for batch setup (change over) for part types $\mathrm{i}$ processed on machine $\mathrm{j}$

Tqc $_{\text {ij }}$ Total time for quality control inspection for part types i completing processing on machine $\mathrm{j}$

$\mathbf{T m h}_{\mathrm{ij}}$ Total move time for part types i processed on machine $\mathrm{j}$

$\mathbf{T p m}_{\mathrm{j}}$ Total time for preventive maintenance on machine $\mathrm{j}$

$\operatorname{Trm}_{\mathrm{j}}$ Total time for repair maintenance on machine $\mathrm{j}$

\section{Rates:}

$\mathbf{R d p}_{\mathrm{j}}$ Depreciation/production hour for machine $\mathrm{j}$

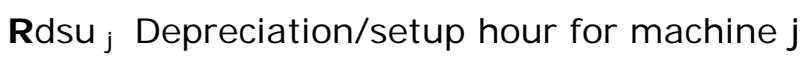

RIp Labor rate for production activities (loading and unloading parts)

RIsu Labor rate for batch setup activities

Rlqc Labor rate for quality control inspections

$\mathbf{R} \mid \mathrm{mh}$ Labor rate for material handling

$\mathbf{R C s}_{\mathrm{j}}$ Consumable supplies rate for machine j

$\mathbf{R g a}_{\mathrm{j}}$ General/Administrative cost/hour for machine j (based on scheduled hours)

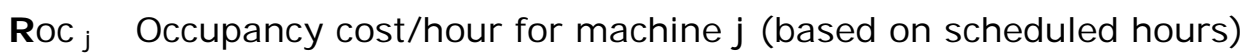

Rir $_{\text {j Installation/Reconfiguration cost for machine } \mathbf{j}}$

$\mathbf{R p}_{\mathrm{j}} \quad$ Operating cost/hour for machine $\mathbf{j}$

Rqc Inspection cost/inspection following machine j

Rpm Preventive maintenance cost/hour

Rrm Repair maintenance cost/hour

Rop Order processing cost/per order 
$\mathbf{R m}$ i Raw material cost per batch for part type i

RI Inventory overhead rate per part

\section{Quantities:}

$\mathbf{N q}$ ij Number of batches of part i processed on machine $\mathrm{j}$

$\mathbf{N} \mathbf{p}_{\text {ij }} \quad$ Number of units of part i processed on machine $\mathbf{j}$

$\mathrm{Na}_{i} \quad$ Number of part type i to enter processing

No ${ }_{i} \quad$ Number of orders for part i

Nlt i Estimated number of part type i to be produced over product life cycle

$\mathbf{N I}_{j} \quad$ Maximum number of parts waiting in the machine $\mathrm{j}$ queue

\section{Costs:}

$\mathrm{Cpc}_{\mathrm{i}} \quad$ Per unit cost for part type i

$\mathrm{Cm}_{\mathrm{i}} \quad$ Per unit procurement cost for part type i

$\mathrm{Cp}_{\mathrm{ij}} \quad$ Per unit production cost for part type $\mathrm{i}$ on machine $\mathrm{j}$

$\mathrm{Cmh}_{\text {i }}$ Per unit material handling cost for part type i

Cmx Per unit maintenance cost

$\mathbf{C d v}_{\mathrm{i}}$ Per unit development cost for part type i

$\mathrm{Cqc}_{\mathrm{i}}$ Per unit inspection/quality control cost for part type $\mathrm{i}$

$\mathrm{Ce}_{i} \quad$ Total cost for part family engineering development

$\mathrm{CC}_{\mathrm{i}}$ Total cost for part family codification

$\mathbf{C t}_{i} \quad$ Total cost for part family tooling and fixtures

$\mathbf{C l}_{\mathrm{j}} \quad$ Per unit inventory overhead cost for machine $\mathrm{j}$

\section{References}

Barth, M., Livet, A., \& De Gui, R. (2008). Effective activity-based costing for manufacturing enterprises using a shop floor reference model. Journal International Journal of Production Research, 46 (3), 621 - 646. doi: $10.1080 / 00207540600845750$

Dhavale, D.G. (1992). Activity-based costing in cellular manufacturing systems. Industrial Engineering, 24, 44-46.

Dhavale, D.G. (1993). Activity-based costing in cellular manufacturing systems. Cost Management, 7, 13-27. 
Emblemsvag, J. (2003). Life-cycle costing: using activity-based costing and monte carlo methods to manage future costs and risk. New York: John Wiley \& Sons.

Flynn, B.B, \& Jacobs, F.R. (2007) Applications and implementation: an experimental comparison of cellular (group technology) layout with process layout. Decision Sciences, 18(4), 562-580.

doi: 10.1111/j.1540-5915.1987.tb01547.x

Groover, M. (1987). Automation, production systems, and computer integrated manufacturing. New J ersey: Prentice-Hall.

Harrison, D.S., \& Sullivan, W.G. (1996). Activity-based accounting for improved product costing. Engineering Valuation and Cost Analysis, 1, 55-64.

Helberg, C., Galletly, J.E., \& Bicheno, J.R. (1994). Simulating activity-based costing. Industrial Management \& Data Systems, 94(9), 3-8. doi: $10.1108 / 02635579410072126$

Hicks, D.T. (1992). Activity-based costing for small and mid-sized businesses: an implementation guide. New York: John Wiley \& Sons.

Lere, J.C., \& Saraph, J.V. (2006). Activity-based costing for purchasing managers' cost and pricing determinations. Journal of Supply Chain Management. 31(4), 2531. doi: 10.1111/j.1745-493X.1995.tb00212.x

MacArthur, J.B. (1992). Activity-based costing: how many drivers do you want? Cost Management, Fall 1992, 37-41.

Malik, S.A., \& Sullivan, W.G. (1995). Impact of abc information on product mix and costing decisions. IEEE Transactions on Engineering Management, 42, 171-176. doi: $10.1109 / 17.387268$

Mangan, T.N. (1995). Integrating an activity-based cost system. Cost Management, Winter 1995, 5-13.

Michalska, J., \& Szewieczek, D. (2007). The improvement of the quality management by the activity-based costing. Journal of Achievements in Materials and Manufacturing Engineering, 21(1), 91-94. 
Özbayrak, M., Akgün, M., \& Türker, A.K. (2004). Activity-based cost estimation in a push/pull advanced manufacturing system. International Journal of Production Economics, 87(1), 49-65. doi:10.1016/S0925-5273(03)00067-7

O'Loughlin, M.J., Driskell, M.K., \& Diehl, G. (1990). Financial simulation: combining cost information in systems analysis. Proceedings of the 1990 Winter Simulation Conference, 578-581.

Raab, C., Shoemaker, S., \& Mayer, K.J. (2007). Activity-based costing: a more accurate way to estimate the costs for a restaurant menu. International Journal of Hospitality \& Tourism Administration, 8(3), 1-15. doi: 10.1300/J149v08n03_01

Savory, P.A., Williams, R.E., \& Rasmussen, R.R. (2001). Combining activity-based costing with the simulation of a cellular manufacturing system. Journal of Design and Manufacturing Automation, 1(3), 221-229. doi: 10.1080/15320370108500204

Shields, M.D., \& McEwen, M.A. (1996). Implementing activity-based costing systems successfully. Cost Management, Winter 1996, 15-22.

Spedding, T.A., \& Sun, G.Q. (1999). Application of discrete event simulation to the activity based costing of manufacturing systems. International Journal of Production Economics, 58(3), 289-301. doi: 10.1016/S0925-5273(98)00204-7

Williams, R.E., Savory, P.A., \& Rasmussen, R.R. (1997). An integrated approach to simulation and activity-based costing for evaluating alternative manufacturing cell designs. Transactions of the XXV North American Manufacturing Research Institute of the Society of Manufacturing Engineers, 263-267.

(c) Journal of Industrial Engineering and Management, 2010 (www.jiem.org)

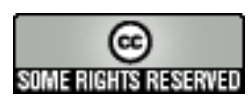

Article's contents are provided on a Attribution-Non Commercial 3.0 Creative commons license. Readers are allowed to copy, distribute and communicate article's contents, provided the author's and Journal of Industrial Engineering and Management's names are included. It must not be used for commercial purposes. To see the complete license contents, please visit http://creativecommons.org/licenses/by-nc/3.0/. 